\title{
Distribution characteristics of dissolved oxygen and stable isotope compositions of shallow groundwater in the vicinity of an inland nuclear power plant, HK, China
}

\author{
Jinjing Zan ${ }^{1,2}$, Yihui Dong ${ }^{1,2, *}$, Weimin Zhang ${ }^{2}$, Weidong $\mathrm{Xu}^{2}$, Jiale $\mathrm{Li}^{1,2}$, Bai $\mathrm{Gao}^{2}$, Fawang \\ $\mathrm{Hu}^{2}$, and Qiaohuan $\mathrm{Wang}^{2}$ \\ ${ }^{1}$ undamental Science on Radioactive Geology and Exploration Technology Laboratory, East China \\ University of Technology, NanChang 330013, China \\ ${ }^{2}$ School of Water Resources and Environmental Engineering, East China University of Technology, \\ Nanchang 330013, China
}

\begin{abstract}
The hydrochemical and stable hydrogen and oxygen isotope compositional characteristics of surface and shallow groundwaters in the vicinity of HK nuclear power plant in Jiangxi Province of China. Dissolved oxygen (DO) contents of shallow groundwaters range between 1.75 to $19.40 \mathrm{mg} / \mathrm{L}$, with variations related to well depth, groundwater level, and oxidation-reduction potential. Respective ranges of $\delta \mathrm{D}$ and $\delta^{18} \mathrm{O}(\%$ VSMOW) in shallow groundwaters are -40.7 to -24.9 and -6.71 to -5.40 , with average values of -31.8 and -5.87 . The $\delta \mathrm{D}-\delta^{18} \mathrm{O}$ relationship for the study area is $\delta \mathrm{D}=8.3 \delta^{18} \mathrm{O}+16.8$, indicating that atmospheric precipitation is the major recharge source of shallow groundwaters.
\end{abstract}

\section{Introduction}

Nuclear power plants provide convenience for human production activities and daily lives. But they will impact the surrounding environment and even cause harm to human health and lead to groundwater contamination by radionuclides. In Japan, the Fukushima nuclear accident caused serious radioactive pollution to the surrounding environment of the nuclear power plant, and the total amount of radioactive material leakage was $520 \mathrm{PBq}$ [1]. After the radionuclide leaks, the migration in shallow groundwater is affected by its redox state. The content of dissolved oxygen (DO) is significantly related to redox state of radionuclides in shallow groundwater [2]. Hydrogen and oxygen isotopes are an effective method for identifying the source of groundwater.

This study examined DO contents and the $\mathrm{H}$ - and $\mathrm{O}$ - composition of surface and shallow groundwaters in the vicinity of $\mathrm{HK}$ - an inland nuclear power plant in Jiangxi Province of China. These results provide an informed basis for monitoring residential health safety near the nuclear power plant.

\footnotetext{
* Corresponding author: yhdong@ecit.cn
} 


\section{Materials and methods}

In the study area, the strata are mainly divided into two layers, the overburden layer is Quaternary unconsolidated sediment and the underlying bedrock is Triassic granite (Fig. 1). There are four aquifer units - a loosely porous aquifer group, a clastic pore fissure aquifer group, a magmatic pore fissure aquifer group, and a metamorphic aquifer group. The climate of the region is warm and humid subtropical, with an abundant annual rainfall of $1547.8 \mathrm{~mm}$. Water from wells and springs is utilized extensively for livestock feeding and potable drinking water.

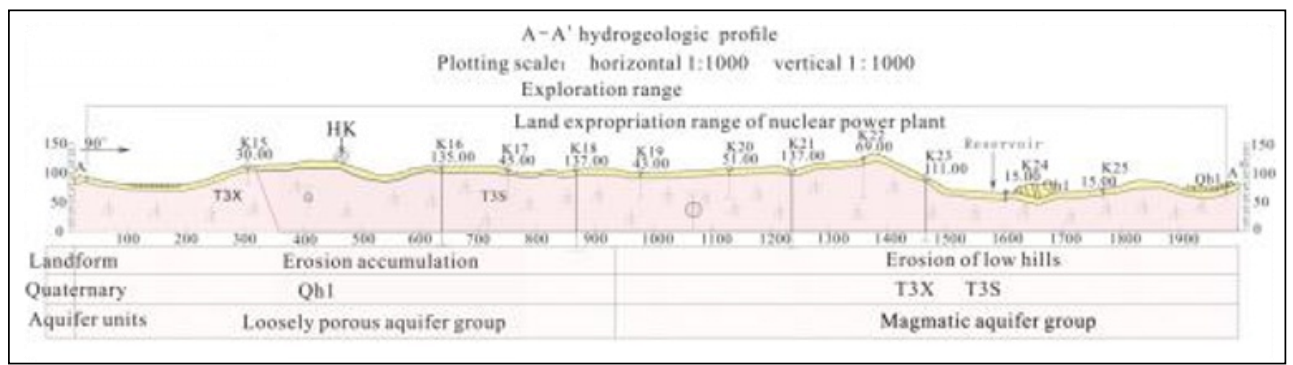

Fig. 1. Regional hydrogeological cross-section map.

In November 2017, 2 surface water samples and 21 shallow groundwater samples were collected in the study area. Oxidation-reduction potential (ORP), $\mathrm{pH}$, electrical conductivity (EC), temperature (T), and DO were measured in situ using Hach Portable Analyzer (Hach, HQ40d). Well depth and water level were measured using portable water stage meter. Alkalinity was titrated by McColor titration apparatus within 24 hours. Samples for isotope analysis were filtered with a $0.45 \mu \mathrm{m}$ PTFE filter and collected in a $5 \mathrm{~mL}$ centrifugal tube with bubbles removed and stored at $4{ }^{\circ} \mathrm{C}$. Stable hydrogen and oxygen isotopes were analyzed by MAT253 mass spectrometer within 24 hours.

\section{Results and discussion}

Table 1 and Table 2 show hydrochemical and stable isotopic compositions of water samples analyzed. Shallow groundwaters in the study area are slightly acidic, and surface waters are of circum-neutral $\mathrm{pH}$.

Table 1. Hydrochemical and stable isotopic compositions of shallow groundwater samples.

\begin{tabular}{|c|c|}
\hline Parameter & average \pm std. dev. \\
\hline Well depth $(\mathrm{m})$ & $4.45 \pm 2.99$ \\
\hline Water level $(\mathrm{m})$ & $2.16 \pm 1.86$ \\
\hline $\mathrm{pH}$ & $6.68 \pm 0.47$ \\
\hline $\mathrm{ORP}(\mathrm{mV})$ & $276.3 \pm 40.8$ \\
\hline $\mathrm{EC}(\mu \mathrm{s} / \mathrm{cm})$ & $168 \pm 148$ \\
\hline $\mathrm{T}\left({ }^{\circ} \mathrm{C}\right)$ & $20.4 \pm 1.9$ \\
\hline $\mathrm{DO}(\mathrm{mg} / \mathrm{L})$ & $7.90 \pm 4.52$ \\
\hline $\mathrm{HCO}{ }^{-}(\mathrm{mg} / \mathrm{L})$ & $52.5 \pm 65.1$ \\
\hline$\delta \mathrm{D}(\%$ vSMOw $)$ & $-31.8 \pm 4.5$ \\
\hline$\delta^{18} \mathrm{O}(\%$ vSMOw $)$ & $-5.87 \pm 0.35$ \\
\hline
\end{tabular}


Table 2. Hydrochemical and stable isotopic compositions of surface water samples

\begin{tabular}{|c|c|c|c|c|c|c|c|}
\hline $\mathrm{pH}$ & $\begin{array}{c}\mathrm{ORP} \\
(\mathrm{mV})\end{array}$ & $\begin{array}{c}\mathrm{EC} \\
(\mu \mathrm{s} / \mathrm{cm})\end{array}$ & $\begin{array}{c}\mathrm{T} \\
\left({ }^{\circ} \mathrm{C}\right)\end{array}$ & $\begin{array}{c}\mathrm{DO} \\
(\mathrm{mg} / \mathrm{L})\end{array}$ & $\begin{array}{c}\mathrm{HCO}_{3}^{-} \\
(\mathrm{mg} / \mathrm{L})\end{array}$ & $\begin{array}{c}\delta \mathrm{D} \\
(\% \text { VSMOw })\end{array}$ & $\begin{array}{c}\delta^{18} \mathrm{O} \\
(\% \text { vsmow })\end{array}$ \\
\hline 7.73 & 293 & 50 & 16.4 & 8.49 & 38.6 & -33.8 & -5.31 \\
\hline 7.40 & 216 & 142 & 20.5 & 8.27 & 36.0 & -49.2 & -4.72 \\
\hline
\end{tabular}

\subsection{DO in shallow groundwater}

As illustrated in Figure 2, groundwater dissolved oxygen content (DO) is negatively correlated with well depth (a) and water level (b), with deeper water levels exhibiting lower DO contents. The pentagonal star in the figures is an anomalous point with DO of 19.40 $\mathrm{mg} / \mathrm{L}$, well depth of $4.50 \mathrm{~m}$, and water level of $4.00 \mathrm{~m}$. The high DO for this sample is likely a consequence of midday photosynthesis by the large algae growth in the well. A positive correlation between DO and oxidation reduction potential (ORP) is observed (Fig. 2c), indicating strongly oxidizing conditions throughout the groundwater environment. In oxidizing environment uranium is in $\mathrm{U}_{\mathrm{VI}}$ state and thus highly mobile [3].

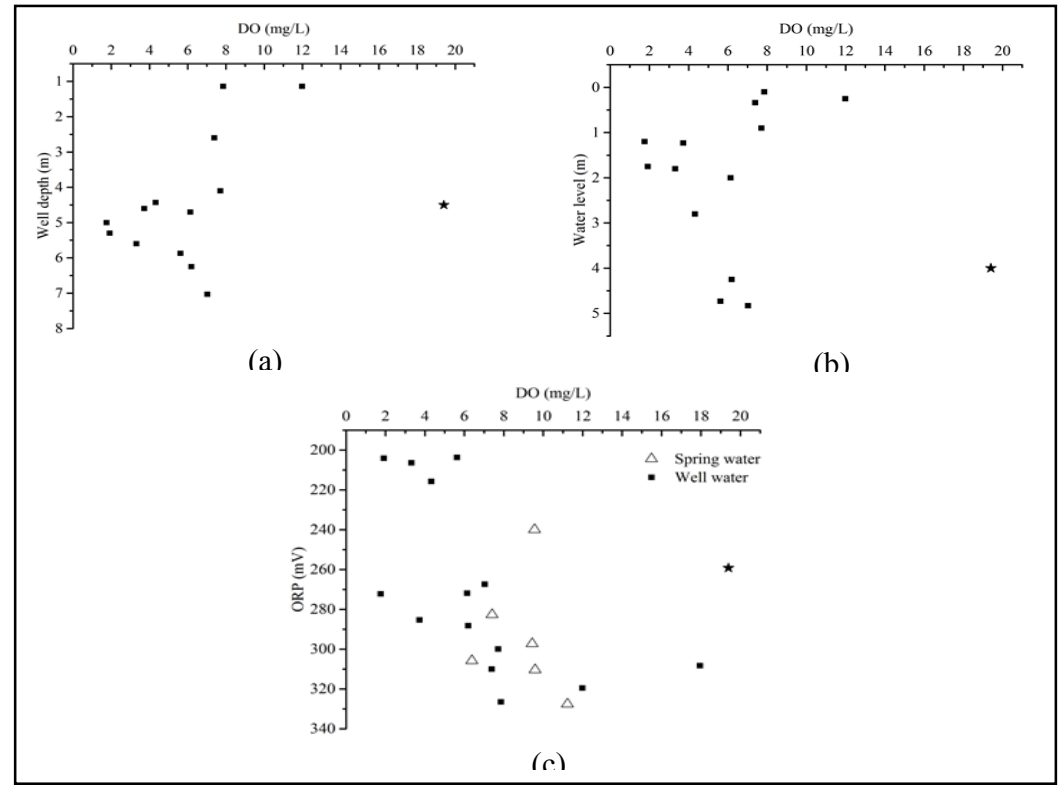

Fig. 2. Plots of DO versus well depth (a), water level (b), and ORP (c) in shallow groundwater samples.

\subsection{Characteristics of stable hydrogen and oxygen isotopes}

Figure 3 shows the correlation between $\mathrm{H}$ - and O- isotope compositions and well depth. With the well depth becoming shallower, the evaporation strengthens and a progressive enrichment in $\mathrm{D}$ and ${ }^{18} \mathrm{O}$ is observed [2]. 
According to the global precipitation data, Craig obtained the Global Meteoric Water Line (GMWL) that is defined by the equation: $\delta \mathrm{D}=8 \delta^{18} \mathrm{O}+10$ [4], while Zheng calculated the China Meteoric Water Line (CMWL), which follows the relationship: $\delta \mathrm{D}=7.9 \delta^{18} \mathrm{O}+8.2$ [5]. Yingtan, Jiangxi Province is $230 \mathrm{~km}$ away from the study area, but has similar climatic conditions, so the Local Meteoric Water Line (LMWL) for Yingtan of $\delta \mathrm{D}=8.61 \delta^{18} \mathrm{O}$ +18.34 ) [6] is used for comparison.

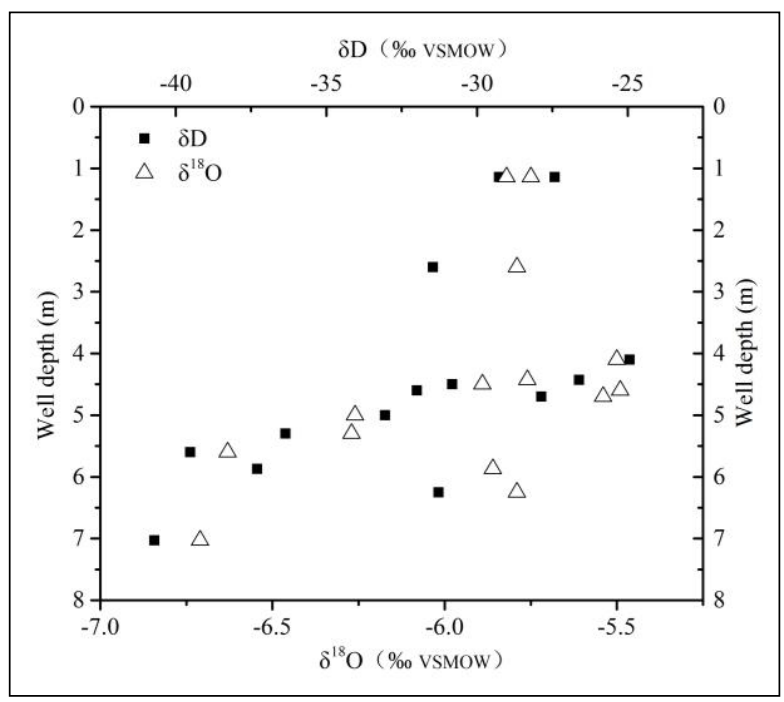

Fig. 3. Relationship between measured H- and O- isotopic composition of shallow groundwaters and well depth.

As illustrated in Figure 4, the H- and O- isotope compositions of shallow groundwater samples in the study area are distributed away from and to the upper-left of the GWML and the CMWL, but fall on both sides of the Yingtan LMWL. With the evaporation and enrichment of isotopes during precipitation, the correlation equation is $\delta \mathrm{D}=8.3 \delta^{18} \mathrm{O}+16.8$, and the slope is close to the slope of the GMWL, indicating atmospheric precipitation is the main recharge source of shallow groundwaters.

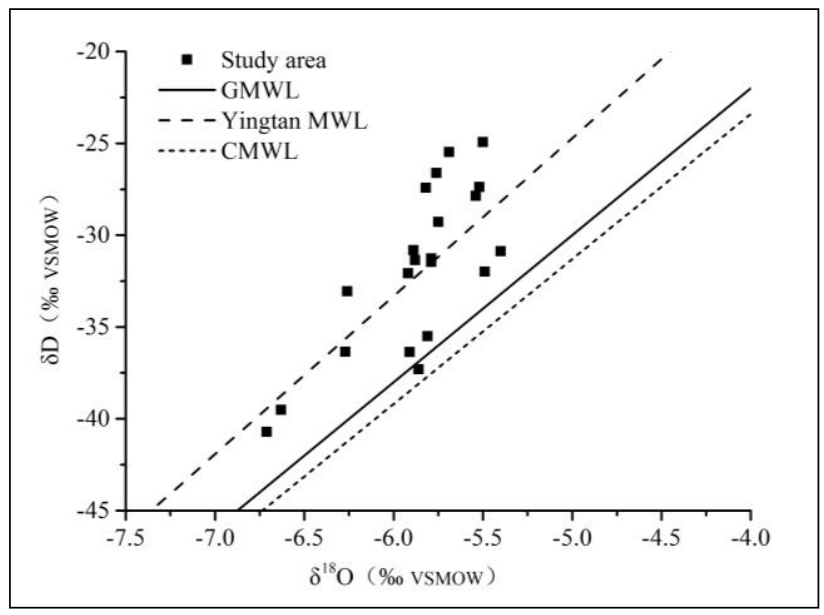

Fig. 4. Plot of $\delta \mathrm{D}$ versus $\delta^{18} \mathrm{O}$ and in shallow groundwaters of the study area showing the Global Meteric Water Line (GMWL), China Meteoric Water Line (CMWL), and Yingtan Local Meteoric Water Line. 
The intercept is larger than that of the GMWL and that of the CMWL, and smaller than that of the Yingtan Meteoric Water Line, indicating that the degree of imbalance between gas and liquid isotope fractionation during the formation of precipitation cloud gas is larger [7].

\section{Conclusion}

This has demonstrated a close hydraulic connection between surface water, well water and spring water, with atmospheric precipitation the main source of shallow groundwater. recharge.

In November 2017, shallow groundwaters in the study area have DO contents that ranged from 1.75 to $19.40 \mathrm{mg} / \mathrm{L}$, with an average of $7.90 \mathrm{mg} / \mathrm{L}$, and ORP values from 204 to $328 \mathrm{mV}$, with an average value of $276 \mathrm{mV}$, indicating strongly oxidizing conditions throughout the groundwater environment. Should the radionuclide element U leak into this strongly oxidizing environment, it will exist in the form of $\mathrm{U}^{6+}$ and migrate with the groundwater aquifer, resulting in radioactive contamination of the surrounding environment.

Acknowledgements. This work was supported by Fundamental Science on Radioactive Geology and Exploration Technology Laboratory, East China University of Technology (RGET1807, RGET1808), the International Atomic Energy Agency Coordinated Research Project (IAEA No. 21122), Open Fund of Jiangxi Key Laboratory for Mass Spectrometry and Instrumentation, East China University of Technology (No. JXMS2017016) and Science and Technology Project Founded by the Education Department of Jiangxi Province (GJJ150596).

\section{References}

1. W. H. Lin, et al., Chin Environ Sci, 35, 269-276 (2015)

2. H. Wang, Hydrogeochemical Characteristics in Faintly Acid Redox Environment, a Case Study of the Wusuli River in Sanjiang Plain (Institute of Disaster Prevention, Sanhe City, 2017)

3. F. Chabaux, et al., Rev. Mineral. Geochem, 52, 533-576 (2003)

4. H. Craig, Science, 133, 1702-1703 (1961)

5. S. H. Zheng, et al., Chin Sci Bull, 28, 801-806 (1983)

6. Y. J. Shen, et al., Eco Environ Sci, 23, 101-105 (2014)

7. H. Shi, et al., J. Soil Water Cons, 17, 163-166 (2003) 